\title{
Fernández, M. D., y Fernández, G. F. (coords.) (2016). La escuela de ayer, hoy y mañana. Claves y desafios. Madrid, España: Dykinson.
}

\author{
JUAN VARELA TEMBRA* \\ Universidad San Jorge - España
}

Recibido el 16-10-20; aceptado el 24-02-21

La historia de la educación permite vislumbrar cómo la escuela ha estado siempre en el ojo del huracán, navegando constantemente entre las vicisitudes políticas de cada momento y, sorprendentemente, sobreponiéndose y saliendo airosa de los vaivenes e intereses político-financieros de turno. A pesar de verse inmersa en esas constantes y variables oscilaciones ideológicas, ha podido prestar a la humanidad un espacio ciertamente libre de desigualdades sociales. No obstante, hoy en día vivimos enfrascados en una crisis de amplio calado, que no es solo una crisis económica. Es decir, asistimos a una crisis política, cultural y de valores. Y para poder sobreponernos a ella, para poder lograr un futuro mejor, surge una imperiosa necesidad que lo abarca todo: la educación, entendida como un derecho que nosotros, mejor o peor, gozamos y consideramos, pero que dista mucho de ser universal en términos reales. De este modo, en la actualidad, se habla más que nunca de educación. Se reflexiona sobre la forma en cómo adaptar la escuela a los grandes desafíos que tenemos ante nosotros, tanto a nivel local como universal. Por ello, resulta más urgente que nunca el que todos los agentes involucrados: profesoras y profesores, madres y padres, universidades, escuelas, cargos públicos, instituciones y, naturalmente, el propio alumnado, reflexionen individual y colectivamente. Tenemos que meditar pausadamente, con un análisis claro y pormenorizado sobre los problemas de la actualidad y sus soluciones posibles para poder decidir lo que tenemos que hacer y qué camino seguir.

\footnotetext{
* Doctor en Didáctica de la Lengua y la Literatura por la Universidad de Murcia. Máster en Promoción de la Lectura y Literatura Infantil por la Universidad de Castilla-La Mancha. Ha trabajado como profesor de Español para extranjeros en el Instituto Politécnico de Castelo Branco y en la Universidad de Santiago de Compostela. Sus campos de estudio tratan de la literatura multicultural infantil y juvenil, la otredad y la alteridad. Actualmente, es profesor tutor de la UNED (A Coruńa) y profesor experto en la Universidad San Jorge (CESUGA). Correo electrónico: jjvarela@usj.es. https://orcid. org/0000-0001-5942-0278
} 
En medio de esta creciente polémica, surge el presente volumen que reúne quince artículos, que como se desprende de su título, constituyen una profunda reflexión, una detallada búsqueda de un nuevo sentido y una mirada crítica hacia la historia de la educación como tema y como proceso histórico en medio del incipiente control por parte del sistema político-económico. Todos estos aspectos son ampliamente abordados en una serie de colaboraciones académicas sobre una temática que tiene como eje vertebrador el origen, el presente y el futuro de una de las instituciones sociales más relevantes y determinantes para la humanidad: la escuela.

Las contribuciones críticas expuestas en la obra se aproximan cuidadosamente a temáticas recurrentes como los nuevos modelos educativos, la educación en valores, la atención a la diversidad y la formación inicial y permanente del profesorado, que surgen a consecuencia de una profunda y concisa reflexión sobre el mundo educativo actual. De ahí que la escuela como institución constituya el eje central y vertebrador de esta introspección por parte de reputados profesionales de la educación y conforme una clara línea de investigación que posibilite la transferencia y la divulgación del conocimiento en torno a la escuela, como puede verse en las páginas que siguen.

La alcaldesa de Lugo, Lara Méndez, afirma en el prólogo de la obra que la escuela constituye una metáfora de la sociedad; una sociedad sumida en constantes y variables torbellinos ideológicos, que busca un camino para dar respuesta a las inquietudes de la ciudadanía de nuestro tiempo. El presente volumen, por tanto, plantea, de manera clara y precisa, algunos de los principales problemas que afectan a la escuela y a sus profesionales. Este es el hilo conductor entre las diferentes secciones de la obra en cada uno de sus ámbitos educativos. Del mismo modo, nos revela la vinculación de la obra con la ciudad de Lugo y con su consistorio, cercano colaborador en su edición.

En la primera sección de la obra, dedicada a las instituciones educativas de la ciudad de Lugo, el profesor Fernández Suárez ofrece, de forma detallada, una compleja visión del pasado que nos permite reflexionar sobre los fundamentos bajo los que se edificaron las escuelas del presente. El proceso y el impacto de la enseńanza en la ciudad de Lugo en la Edad Moderna se aborda desde la perspectiva de la época. Surge así el papel omnipresente de la Iglesia y del clero como guardianes de la ortodoxia y custodios de esta. La conclusión más relevante que el ilustre autor del estudio nos acerca es la consideración del nacimiento de unas estructuras, que, con el devenir de los tiempos, tendrán un profundo arraigo social, volviéndose parte del imaginario social colectivo de la ciudad y de su provincia. 
El segundo capítulo de la obra está firmado por Juan Carlos Pardo Pérez, quien analiza la escuela en la era de la modernidad y del renacimiento, así como en la época postmoderna de la que formamos parte y que se encuentra absorta en el enfoque por competencias que se erige en un resorte ideológico y tecnocrático que favorece la selección y clasificación del alumnado. Este estudio, nos refiere, fundamentalmente, cómo la escuela se presenta como una institución moderna y revolucionaria, surgida con la trascendental labor de formar a ciudadanos y ciudadanas libres e iguales, aptos para tomar parte activa en el avance social y en el desarrollo moral.

Los capítulos tercero y cuarto, a cargo de Belisario Sixto San José y Manuel Losada Cabanas, respectivamente, nos aportan una perspectiva de la más reciente regulación legislativa de nuestro sistema educativo, atendiendo, en primer lugar a los cambios introducidos por la Ley Orgánica 2/2006, de 3 de mayo, de Educación LOE y la Ley Orgánica 8/2013, de 9 de diciembre, para la mejora de la calidad educativa (LOMCE) y, en segundo lugar, a su desarrollo y concreción curricular en Educación Infantil y Primaria y en Secundaria en la Comunidad Autónoma de Galicia, poniendo de manifiesto las finalidades, intenciones, organización y regulación del currículo entre otros factores a tener en consideración.

En el quinto capítulo, el investigador José Manuel Suárez Santodomingo recalca la importancia de la familia como lugar principal para la educación en valores en el marco de una profunda reflexión sobre los valores sociales y educativos. En ese contexto, se nos evoca el hecho de que la educación en sí está imbuida de valores suscitados en la primera comunidad educadora, la familia, la cual tiene como misión el legado y transmisión de estos de generación en generación.

A continuación, en el sexto capítulo, la profesora Pilar Quicios García toma en consideración la atención a la diversidad en la escuela como un factor que previene el riesgo social infantil y juvenil. Una atención a la diversidad en nuestro país que insiste en la necesidad de que el profesorado disponga de la formación didáctica y pedagógica adecuada que requiere el poder dar respuesta a las necesidades específicas de apoyo educativo entre el alumnado de nuestros centros.

El capítulo séptimo, a las puertas del ecuador de la obra, a cargo de la Alcínia Noutel, experta en la materia de referencia, hace hincapié en la situación por la que pasan aquellos jóvenes que sufren tóxico dependencia resaltando la relevancia de una pronta intervención para su prevención, aspecto fundamental que no podría llevarse a cabo sin el apoyo de las familias y el respaldo de la escuela. 
Volviendo a incidir en la importancia y relevancia de la atención a la diversidad, Iker Sertucha Lista se centra en la situación educativa que afecta al alumnado que padece sordera y pérdida de la audición. A pesar de reconocer el aumento de recursos humanos y materiales destinados a su atención educativa individualizada, el autor pone de manifiesto que ese aumento en los niveles de escolarización de ese colectivo no ha tenido como resultado una mayor integración.

Las profesoras doctoras María Laura Malvar Méndez y María Dolores Fernández Tilve exploran, en el octavo capítulo, con gran acierto, los documentos que regulan la praxis orientadora en Galicia, marcada por un perfil profesional articulado fundamentalmente en competencias asociadas al «saber ser» y «saber estar». Los diferentes ejemplos que se pueden apreciar en su contribución proporcionan un amplio abanico de retos educativos de plena actualidad y de propuestas formativas para trabajar y promover las competencias y saberes de los profesionales de la educación.

En el siguiente capítulo, con un título muy sugerente, el profesor Quintín Álvarez Núñez presta una especial atención a la imperiosa necesidad de introducir la educación emocional en la escuela. El investigador hace un especial énfasis en que este propósito trascienda a todos los niveles del centro educativo para llevar a cabo una variación sustancial en su tradicional enfoque instructivo, dejando atrás la mera transmisión de contenidos y avanzando hacia un modelo precursor del desarrollo de la inteligencia emocional e inteligencias múltiples.

El capítulo once, a cargo de Antonio Rial Boubeta y Patricia Gómez Salgado, en el que plantean uno de los retos a los que tiene que enfrentarse la escuela del siglo XXI, ya que más allá de los prejuicios o riesgos que puedan estar asociados a un uso excesivo o abusivo de Internet y las Redes Sociales, nos encontramos con una falta de madurez y de empatía en la gestión de las emociones de nuestros jóvenes que puede llevar consigo consecuencias muy negativas, llegando a ser prácticas de alto riesgo social o incluso delitos penales, como son el sexting, el ciberbulling o el groming que tanta preocupación suscitan en nuestras comunidades socioeducativas. El profesorado de hoy en día deben hacer frente a esa nueva realidad, desarrollando procesos de intervención educativa.

La parte final de la obra, compuesta por los capítulos que van de doce al quince, tienen como eje central el profesorado y su formación tanto inicial como continua. El capítulo doce firmado por Eduardo Fuentes Abeledo y Nuria Abal Alonso, profundiza en esa formación inicial, tan necesaria, de los futuros maestros de cara a su futuro ejercicio profesional. Por otro lado, María Dolores Fernández Tilve y Marta Poncet Souto en el capítulo trece, estudian 
el proceso de construcción profesional del alumnado que comienza Grado de Educación Primaria y lo vinculan con las motivaciones para elegir la profesión docente. El penúltimo capítulo, a cargo de José María Aguilera Carrasco, presta especial atención a los desafíos que deben contraer las instituciones educativas y sus profesionales de cara a la introducción de las TIC en el aula.

Finalmente, Ana María Baena Ampudia y María Dolores Fernández Tilve cierran la obra reflexionando sobre el rol de los sindicatos como agentes en la formación continua del profesorado, partiendo de que la misma es considerada un derecho y una obligación de todo el profesorado. Se toma como punto de partida la asunción de que la renovación pedagógica, la innovación educativa y la investigación tanto fuera como dentro del aula conforman una parte de las competencias docentes que permiten suscitar y promover el avance permanente de los procesos de enseñanza y aprendizaje en las distintas etapas y niveles académicos. De este modo, ante una sociedad que se encuentra sumida en un cambio y readaptación casi continuos, el método de aprendizaje de los alumnos ha alterado sus premisas y coyuntura que ya no son las que podían haber sido hace diez años, ni la posible respuesta educativa será la misma en un futuro cercano. Las vicisitudes propias de cada centro educativo y las particularidades del alumnado y su entorno acreditan la necesidad de una formación permanente del profesorado durante toda su trayectoria profesional para avalar la adaptación de la educación a la situación del momento.

Sin lugar a duda, podemos concluir que en un contexto como el actual, en el que la escuela tiene que hacer frente a un número considerable de desafíos, precisamos sopesar y reflexionar constructivamente sobre el cariz que debe tomar una institución a la que la sociedad ha encomendado la formación de la ciudadanía. Así pues, con un gran trasfondo como este, cobra gran relevancia un libro como este que aborda sin tapujos algunos de los principales problemas presentes en la actualidad en la escuela. Con toda seguridad, esta obra, que constituye una clara reflexión colectiva, tiene la clara vocación de favorecer la transmisión y divulgación del conocimiento, como ha podido verse en las páginas analizadas. Los colaboradores, reputados agentes educativos, dejan buena constancia de ello. Confiamos que esta publicación pruebe su utilidad y permita permanecer en el tiempo a las contribuciones presentadas con rigor y compromiso científico.

\section{REFERENCIAS BIBLIOGRÁFICAS}

Fernández, M. D. y Fernández, G. F. (coords.) (2016). La escuela de ayer, hoy y mañana. Claves y desafios. Madrid, España: Dykinson. 